\title{
Relacje semantyczne w polskich i niemieckich terminach wielowyrazowych z zakresu prawa
}

Słow a klucze: terminy wielowyrazowe; terminy złożone; kompozycje; relacje semantyczne; terminologia prawna

Ke y w ord s: multi-word terms; compound terms; compositions; semantic relations; legal terminology

\section{Termin, termin złożony, termin wielowyrazowy - wyjaśnienie pojęć}

Teksty prawne i prawnicze to teksty informacyjne, charakteryzujące się wysokim stopniem precyzji przekazywanych treści. Nie dziwi zatem ich nasycenie terminami, a w szczególności terminami złożonymi, które nazywają instytucje i stany prawne za pomocą minimum dwóch (lub więcej) różnicujących cech (por. Iluk 2012a: 162). Preferowanie terminów złożonych wynika głównie z tendencji języków specjalistycznych do intelektualizacji (por. Sitarski 1981: 184), czyli „,nadani[a] językowi takich cech, które uprawniają go szczególnie do funkcji języka nauki - przede wszystkim jest to jednoznaczność i precyzja" (I. Bajerowa 1972: 31).

Termin określany jest w literaturze jako „wyraz (połączenie wyrazowe) o konwencjonalnie określonej, ściśle zdefiniowanej strukturze pojęcio- 
wej, w zasadzie jednoznaczny i nie podlegający interpretacji o charakterze emocjonalnym, posiadający natomiast zdolności systemotwórcze. [...] [T]o znak językowy należący do leksykonu określonego technolektu i oznaczający pojęcie w systemie relacji semantycznych właściwych dla tego leksykonu” (Lukszyn / Zmarzer 2006: 21). Współczesne teorie terminologii poza funkcją reprezentacyjną i standaryzacyjną podkreślają funkcję socjalną terminów, tj. potrzebę ich akceptacji przez środowisko specjalistów (por. m.in. Tomaszczyk 2014: 61, A. Bajerowska 2014: 89). Koncepcja socjokognitywna Temmermana (2000) odchodzi od statycznej definicji terminów i postrzega je jako jednostki, które „,nabierają znaczenia i ewoluują wraz z rozwojem dyscypliny, do której należą” (Tomaszczyk 2014: 63). ,[...] [T]erminy nie reprezentują już rzeczywistości, ale myśli o rzeczywistości i stan wiedzy w wybranej dziedzinie, w której tworzenie nowych terminów świadczy o ewolucji myśli w tej dziedzinie" (Tomaszczyk 2014: 63).

Terminy mogą występować jako formy proste lub złożenia. Człony tworzące termin złożony mogą być zespolone bez fleksyjnych wykładników relacji syntaktycznych (kompozycja) albo z eksplicytnie wyrażonymi relacjami syntagmatycznymi (termin wielowyrazowy) (por. Iluk 2012a: 162). Terminy wielowyrazowe - inaczej, wielowyrazowe jednostki leksykalne (Pałuszyńska 1998), skupienia terminologiczne (Starzec 1984); w języku niemieckim Mehrworttermini lub phraseologische Termini - to wielowyrazowe zwroty określające obiekty i stany rzeczy charakterystyczne dla pewnej dziedziny specjalistycznej, często zawierające inny termin, prosty, jako jeden ze swych komponentów, np. deficyt budżetowy / das öffentliche Defizit. Starzec (1984: 62) definiuje terminy wielowyrazowe jako: „,[p]ołączenie dwu- lub więcejwyrazowe spełniające rolę jednostki nominacyjnej w ramach określonej dziedziny wiedzy" (Starzec 1984: 62). Terminy wielowyrazowe mają ściśle określone, jednoznaczne i unormowane znaczenie w obrębie określonego idiolektu specjalistycznego (por. m.in. Burger 1998: 47; Fluck 1985: 47). Do pozostałych cech terminów wielowyrazowych zalicza się stabilność ich komponentów, reprodukcyjność, leksykalizację, neutralność stylistyczną i konwencjonalne użycie, a także do pewnego stopnia idiomatyczność znaczenia (por. Gajda 1990; Delplanque-Tchamitchian 1995: 40), jak w przypadku terminów rzecz ruchoma / bewegliche Sache czy akcja niema / stimmrechtslose Aktie.

Szczególną grupą terminów wielowyrazowych, często występującą w tekstach prawnych i prawniczych, są wyrażenia onimiczne (por. Burger et 
al. 1982: 38), stanowiące jednostki nominacyjne m.in. dla określenia instytucji, organów czy środków prawnych, np.:

\section{Przewodniczacy Parlamentu Europejskiego / der Präsident des Europäi- schen Parlaments}

Prokuratura Europejska / die Europäische Staatsanwaltschaft

Statut Trybunału Sprawiedliwości Unii Europejskiej / Satzung des Gerichtshofs der Europäischen Union

\section{Tworzenie terminów wielowyrazowych}

Kryteria terminu spełniają jedynie te jednostki leksykalne, a zatem także te struktury wielowyrazowe, które wykazują odpowiedni stopień terminologizacji, czyli wskaźnik wyrazistości oznaczonego pojęcia specjalnego (por. Górnicz 2003: 107). Lukszyn (2002: 102) wskazuje na trzy etapy terminologizacji istniejących jednostek leksykalnych: (1) wstępną fiksację pojęcia z danej dziedziny, na skutek której wyraz ogólny staje się preterminem, (2) ścisłą konceptualizację znaku językowego, której produktem jest quasi-termin oraz (3) optymalną definicję pojęcia, której produktem jest termin. Wszystkie trzy produkty etapów terminologizacji służą przekazywaniu pojęć specjalistycznych (por. Górnicz 2003: 107), dlatego też w dalszych rozważaniach będą one zaliczane do grupy terminów wielowyrazowych bez uwzględniania ich różnego stopnia terminologizacji.

Część terminów wielowyrazowych była pierwotnie luźnymi związkami syntagmatycznymi, które pod wpływem skonwencjonalizowanego użycia stały się stałą nominacją (por. Busse 2002: 411). Konwencjonalny charakter terminów wielowyrazowych podkreśla na przykładzie terminów prawnych Iluk (2012b: 98), według którego połączenie członów terminów wielowyrazowych bazuje na konwencji przyjętej m.in. w ustawach, zaś znaczenie terminu określone jest normami prawnymi przyjętymi przez prawodawcę lub kontekstem.

Terminy wielowyrazowe powstają $\mathrm{w}$ wyniku derywacji syntagmatycznej (por. Siewert 2010: 84) zwanej syntaktyczną (por. Sitarski 1981: 183). W języku polskim występują znacznie częściej niż w niemieckim. W wielu polskich terminologiach specjalistycznych derywacja syntagmatyczna jest 
najczęstszym i najbardziej produktywnym modelem tworzenia nowych terminów i stanowić możne nawet $80-90 \%$ dla niektórych terminologii (por. Gajda 1990:96). Dla języka niemieckiego bardziej typowe są kompozycje, uważane za najważniejszy i najbardziej produktywny proces słowotwórczy (por. Engel et al. 2000: 750). Engel (2000: 750) wskazuje, że jedynie nielicznym kompozycjom w języku niemieckim odpowiadają kompozycje w języku polskim. Kontrastywne analizy terminologiczne potwierdzają tę tezę także w odniesieniu do polskich i niemieckich języków specjalistycznych. Niemieckim kompozycjom często odpowiadają terminy wielowyrazowe w języku polskim (por. Woźniak 2016: 163).

\section{Budowa terminów wielowyrazowych}

Ze względu na budowę i sposób zespolenia terminy wielowyrazowe dzielimy na struktury typu:

- $\quad \mathrm{N}+$ Adi / Adi+N ewentualnie Part+N / N+Part ${ }^{1}$

W języku niemieckim ze względu na reguły gramatyczne terminy wielowyrazowe występują jedynie jako połączenie przymiotnika w prepozycji i rzeczownika w postpozycji (Adi+N). W języku polskim dopuszcza się struktury z przymiotnikiem w prepozycji, ale jest to zjawisko rzadsze. Jak podaje Engel (2000: 921) przymiotnik w języku polskim w prepozycji wskazuje zwykle na akcydentalny, zaś w postpozycji na trwały charakter cechy. $\mathrm{W}$ polskich terminach wielowyrazowych zarówno przymiotnik w pre- jak i postpozycji wskazuje na stałą cechę terminu a sama pozycja przymiotnika jest uwarunkowana zwyczajem językowym:

kradzież rozbójnicza / räuberischer Diebstahl

wolny zawód / die freiberufliche Tätigkeit

przestępczość zorganizowana / die organisierte Kriminalität

\footnotetext{
${ }^{1} \mathrm{~N}$ - nomen - rzeczownik, Adi - adiektivum - przymiotnik, Part - participium imiesłów
} 
- $\quad \mathrm{N}+\mathrm{N}$

Struktura terminów wielowyrazowych będących połączeniem dwóch (lub więcej rzeczowników) jest bardziej złożona. W języku polskim wyróżnić można m.in. następujące połączenia:

$\mathrm{N}+\mathrm{N}_{\text {Gen }}^{2}$

płody ziemi / Erzeugnisse des Bodens

$\mathrm{N}+\mathrm{N}_{\text {Gen }}+$ Adi

projekt aktu prawodawczego / der Entwurf eines Gesetzgebungsakts

$\mathrm{N}+\mathrm{N}_{\text {Gen }}+\mathrm{N}_{\text {Dat }}^{3}$

misje zapobiegania konfliktom / Aufgaben der Konfliktverhütung

$\mathrm{N}+\mathrm{N}_{\text {Gen }}+\mathrm{N}_{\text {Gen }}$

misje utrzymywania pokoju / Aufgaben der Erhaltung des Friedens

$\mathrm{N}+\mathrm{N}_{\text {Instr }}{ }^{4}$

handel kobietami i dziećmi / Handel mit Frauen und Kindern.

W języku niemieckim występują głównie połączenia typu: $\mathrm{N}+\mathrm{N}_{\mathrm{Gen}}$ (niekiedy rozszerzone o przydawki: przymiotną lub rzeczownikową).

- $\mathrm{N}+\mathrm{PP}^{5}$

akty o zasięgu ogólnym / Rechtsakte mit allgemeiner Geltung pakt o nieagresji / der Nichtangriffspakt.

${ }^{2} \mathrm{~N}_{\mathrm{Gen}}$ - rzeczownik w dopełniaczu

${ }^{3} \mathrm{~N}_{\text {Dat }}$ - rzeczownik w celowniku

${ }^{4} \mathrm{~N}_{\text {Instr }}$ - rzeczownik w narzędniku

${ }_{5} \mathrm{PP}$ - fraza przyimkowa 


\section{Relacja semantyczna między komponentami terminów wielowyrazowych}

Terminy wielowyrazowe z zakresu prawa nazywają w szczególności instytucje, strony postępowania, procedury, kary, akty prawne, czyny zabronione itd. Składają się one, podobnie jak terminy złożone, z n a d r z ę d n i k a - wyrazu określanego - i p o dr zę d n i ka - wyrazu określającego. Motywacja poszczególnych komponentów i relacje między nimi są uzależnione od tego, co terminy te nazywają i czym nazywane zjawisko się charakteryzuje. Znaczenie relacji odpowiada zwykle znaczeniu parafrazy danego terminu złożonego w formie zdania względnego (por. Ortner et al. 1991: 119), np.:

dtugoterminowe stopy procentowe $=$ stopy procentowe, które zostały ustalone na długi okres

[Na jak długo? relacja czasu]

die langfristigen Zinssätze = Zinssätze, die für einen längeren Zeitraum festgesetzt wurden

[Für wie lange? temporale Relation].

W literaturze polskiej i niemieckiej istnieje wiele klasyfikacji relacji semantycznych między komponentami terminów wielowyrazowych i złożonych. Wymienić należy tu choćby Henzena (1957), Morcińca (1964, 2012), Eichingera (2000), Fleischera/Barz (2007), Bizukojć (2011) dla terminów niemieckich, a także Tomasik-Beck (1992) czy Pałuszyńską w odniesieniu do terminologii polskiej. I choć klasyfikacje te $\mathrm{w}$ dużym stopniu pokrywają się ze sobą, różnią się one stopniem szczegółowości. Tomasik-Beck (1992) wymienia 15 typów relacji, przy czym nie zamyka ona zbioru, zwracając uwagę, że mogą wystąpić także inne. Fleischer i Barz (2007) wyróżniają 17 typów dla złożeń rzeczownikowych i 4 dla połączeń Adi+N.

Niemieckie klasyfikacje relacji semantycznych w terminach odnoszą się do terminów złożonych (kompozycji). Możliwość uniwerbizacji przynajmniej części z polskich terminów wielowyrazowych stanowi jednak przesłankę, by przyjąć, iż podobne relacje semantyczne jak w terminach wielowyrazowych będą występowały także w terminach złożonych. Zasadne jest więc skorzystanie z kryteriów użytych do analizy terminów złożonych, aby zbadać moż- 
liwe relacje semantyczne zachodzące między komponentami terminów wielowyrazowych. Nie oznacza to jednakże, że termin złożony (skonsolidowany) jest tożsamy z odpowiadającą mu syntagmą (por. Bizukojć 2011: 17), gdyż kompozycję cechuje wyższy stopień połączenia i zwięzłości (por. Ortner/ Ortner 1984). Ponadto między kompozycją a odpowiadającą mu syntagmą mogą występować istotne różnice semantyczne. I tak niemiecki termin Bürgerrecht oznacza prawa obywatela, tj. prawa wynikające z relacji między państwem a obywatelem. Jest to zatem termin z zakresu prawa publicznego. Pokrewny mu termin wielowyrazowy bürgerliches Recht to polski odpowiednik prawa cywilnego, które tworzy odrębną do prawa publicznego gałąź prawa.

Poniżej podjęto próbę przedstawienia relacji semantycznych zachodzących między komponentami polskich wielowyrazowych terminów prawnych i prawniczych oraz ich niemieckich odpowiedników. W tym celu za kryteria obrano relacje zestawione przez Bizukojć (2011), które opierają się na dwóch wiodących klasyfikacjach niemieckich Eichingera (2000) oraz Fleischera i Barz (2007). W uzupełnieniu opisu kryteriów posłuży polska klasyfikacja autorstwa Beck-Tomasik (1992). Poddane analizie terminy i ich odpowiedniki niemieckie pochodzą z wybranych aktów prawnych UE, w szczególności z Traktatu Lizbońskiego, oraz Słownika języka prawniczego i ekonomicznego autorstwa Kilian/Kilian (2009/2011). W przykładach w celu ułatwienia opisu nadrzędnik został pogrubiony. Ponadto w zestawieniu dla określenia nadrzędnika stosuje się literę $\mathrm{A}$, zaś podrzędnika B.

\section{(1) Relacja czynnika działającego}

Nadrzędnik nazywa stan, instrument, proces lub system prawny, który stanowi efekt działania organu lub osoby prawnej wyrażonej w podrzędniku.

B wydaje $A$

$B$ świadczy / dokonuje A

B sprawuje A

orzeczenie sadowe

gerichtliche Entscheidung

ochrona konsularna der konsularische Schutz
Sąd wydaje orzeczenie.

Das Gericht trifft die Entscheidung.

Konsul świadczy pomoc.

Der Konsul leistet den Schutz. 


\section{(2) Relacja strony biernej}

Osoba lub obiekt wyrażony w nadrzędniku, jest poddawany czynności wyrażonej w podrzędniku.

A zostaje poddany $B$

uproszczona procedura zmiany

das vereinfachte Änderungsverfahren

tytut egzekucyjny

der vollstreckbare Titel procedura zmiany, która została poddana uproszczeniu

Änderungsverfahren, das vereinfacht wurde

tytuł, który jest egzekwowany lub ma być egzekwowany

Titel, der vollstreckt wird oder zu vollstrecken ist

\section{(3) Relacja miejsca i kierunku}

Nadrzędnik wskazuje na przedmiot, który znajduje się w danym miejscu lub zmierza do niego, na czynność, która odbywa się w danym miejscu lub też na przepis prawny, który jest uregulowany w danym źródle prawa. Podrzędnik wskazuje na to miejsce lub źródło.

A działa w $B$

$A$ wydarza sie $w B$

$A$ znajduje się w $B$

A wynika z $B$

A jest uregulowany/określony w $B$

wtadze regionalne

regionale Gebietskörperschaften

wypadek przy pracy

der Arbeitsunfall

stosunek umowny

die vertragliche Beziehung władze, które działają w regionie

Gebietskörperschaften, die in der Region handeln

wypadek, który zdarzył się przy wykonywaniu pracy

ein Unfall, der bei der Arbeit passiert ist

stosunek wynikający z umowy

die Beziehung, die aus dem Vertrag resultiert 
przedstawiciel ustawowy gesetzlicher Vertreter przedstawiciel określony w ustawie

Vertreter, der im Gesetz bestimmt ist

\section{(4) Relacja czasu}

Nadrzędnik nazywa stany rzeczy, akty lub instrumenty prawne. Podrzędnik wskazuje na czas ich trwania/ obowiązywania.

A trwa B

A obowiazuje B

A zostaje założony / uchwalony / orzeczony na okres B

ochrona tymczasowa

vorläufiger Schutz

lokata dtugoterminowa

Daueranlage ochrona, która została wprowadzona/ zapewniona tymczasowo

Schutz, der vorläufig eingeführt wird/ gesichert ist

lokata pieniędzy, założona na długi okres Geldanlage, die für eine längere Zeit/ Geld, das für eine längere Zeit angelegt wird

\section{(5) Relacja celu}

Podrzędnik wskazuje na cel, zastosowanie lub przeznaczenie desygnatu wyrażonego w nadrzędniku.

A zostat wprowadzony/ jest prowadzony w celu $B$

A ma na celu $B$

A zostaty podpisane/ uchwalone / zawarte w celu B

„ustawa naprawcza” 6

Reformgesetz ustawa, która jest uchwalana w celu naprawy istniejącej sytuacji prawnej, ekonomicznej lub społecznej

Gesetz, das eine Reform der bereits bestehenden rechtlichen, wirtschaftlichen oder sozialen Situation zum Ziel hat

6 Termin nie posiada definicji legalnej. Został zaczerpnięty z aktualnych artykułów prasowych. W większości wypadków pisany w cudzysłowie, co świadczy o jego charakterze neologicznym. Posiada odpowiednik w niemieckim systemie prawa. 
przedsiębiorstwo handlowe

Handelsunternehmen przedsiębiorstwo, którego celem jest prowadzenie działalności handlowej

ein Unternehmen, dessen Ziel die Ausübung eines Handelsgewerbes ist

\section{(6) Relacja przyczynowa}

Podrzędnik wskazuje na przyczynę wystąpienia zjawiska określonego w nadrzędniku. $\mathrm{W}$ terminach prawnych w odróżnieniu od terminów technicznych zarówno w nadrzędniku, jak i podrzędniku zjawiska i czynniki mają zwykle charakter abstrakcyjny.

A jest wywolany przez $B$

A powstaje w wyniku $B$

A jest udzielany/wyptacany w przypadku $B$

A dokonuje się ze względu na B

kryzys spekulacyjny

Spekulationskrise

prześladowanie z powodu rasy

Verfolgung wegen Rasse kryzys, który jest wywołany nadmierną spekulacją na rynku

Krise, die durch Spekulation hervorgerufen wird

prześladowanie osoby, którego dokonuje się ze względu na jej rasę

Verfolgung einer Person, die wegen deren Rasse vorgenommen wird

\section{(7) Relacja instrumentalna}

Podrzędnik wskazuje na narzędzie, przy pomocy którego realizowana jest czynność określona w nadrzędniku.

czynność A świadczona jest / dokonywana jest przy pomocy $B$

pomoc finansowa

die finanzielle Hilfe

napaść zbrojna

der bewaffnete Angriff pomoc świadczona przy pomocy środków finansowych

Hilfe, die mit finanziellen Mitteln geleistet wird

napaść, której dokonuje się z pomocą broni i środków wojskowych

Angriff, die jemand mit einer Waffe ausführt 


\section{(8) Relacja porównawcza}

Zjawisko wyrażone w podrzędniku, jego sposób funkcjonowania lub skala są porównywane do innych obiektów lub zjawisk wyrażonych w nadrzędniku. Terminy motywowane relacją porównawczą mają charakter częściowo idiomatyczny. Dlatego ich występowanie w języku prawnym i prawniczym jest rzadkie.

B przypomina $A$

A przypomina $B$

fala imigracyjna

Einwanderungswelle

imigracja, która ze względu na skalę przypomina falę

Einwanderung, die wegen ihrer Intensität einer Welle ähnelt

\section{(9) Relacja adhezyjna}

Organ lub osoba wyrażona w nadrzędniku wchodzi w skład gremium nazwanego przez podrzędnik.

A wchodzi w sktad B

Sędzia Sądu Najwyższego

Richter am Obersten Gerichtshof

Przewodniczacy Parlamentu

Europejskiego

der Präsident des Europäischen

Parlaments
Sędzia, który wchodzi w skład Sądu Najwyższego

Richter, der Mitglied des Obersten Gerichtshofs ist

Przewodniczący, który wchodzi w skład Parlamentu Europejskiego

Präsident, der Mitglied des Europäischen

Parlaments ist

\section{(10) Relacja cząstkowa}

Nadrzędnik wskazuje na obligatoryjną część podrzędnika.

A jest częścia $B$ 
petitum pozwu

[Klagebegehren] pierwsza część pozwu

*Begehren, das in der Klage formuliert wurde [relacja miejsca i kierunku]

\section{(11) Relacja dzierźawcza}

Nadrzędnik określa przedmiot lub środki będące własnością osoby lub instytucji nazwanej przez podrzędnik albo też przysługujące im prawo.

A należy do $B$

A przystuguje $B$

$B$ dysponuje A

wlasność państwowa

staatliches Eigentum

gminne fundusze celowe

Gemeindzweckfonds własność, która należy do państwa

Eigentum, das dem Staat gehört

fundusze celowe, które należą do gminy

Zweckfonds, über die die Gemeinde verfügt

\section{(12) Relacja konstytucjonalna}

Nadrzędnik składa się z elementów/ osób wyrażonych w podrzędniku.

A sktada się z B

Rada Ministrów

Ministerrat

katalog kar i środków karnych Strafenkatalog / Bußgeldkatalog

procedura dwustopniowa das zweistufige Verfahren
Rada, która składa się z ministrów

Rat, der aus Ministern besteht

katalog, który składa się z kar i środków karnych

Katalog, in welchem Strafen und Bußgelder genannt sind

procedura, która składa się z dwóch stopni Verfahren, das aus zwei Stufen besteht

\section{(13) Relacja ornamentalna}

Obiekt wyrażony w nadrzędniku występuje wraz z elementem wymienionym w podrzędniku. Elementy ornamentalne występują w precyzyjnym na- 
zewnictwie języka prawa niezwykle rzadko. Relację ornamentalną w terminach prawnych można jednakże rozumieć bardziej abstrakcyjnie jako:

obiekt/dokument A uzupetniony o określona informację B czynność konwencjonalna A rozszerzona/ wzbogacona o element $B$.

rozwód z orzekaniem o winie

Scheidung wegen Verschuldens rozwód, orzeczony z podaniem osób winnych rozpadu małżeństwa *Scheidung, die wegen Verschuldens eines Ehepartners erfolgt [relacja przyczynowa]

sygnatura, którą są oznaczone akty prawne Zeichen, mit welchem Akten versehen sind sygnatura akt

Aktenzeichen

\section{(14) Relacja tematyczna / relacja zakresowa (Eichinger 2000 )}

Podrzędnik nazywa zakres tematyczny, którego dotyczy stan rzeczy, proces lub czynność wyrażona w nadrzędniku lub też ich zakres obowiązywania.

$A$ dotyczy $B$

$B$ jest tematem $A$

A obejmuje swa regulacją $B$

dane osobowe

personenbezogene Daten

pakt o nieagresji

der Nichtangriffspakt

akt o zasięgu ogólnym

Rechtsakte mit allgemeiner Geltung dane, które odnoszą się do osób

Daten, die sich auf Personen beziehen

pakt dotyczący nieagresji

Pakt über die Unterlassung von Angriffen

akt, który ma ogólny zasięg

Rechtsakte, die allgemeingeltend sind

\section{(15) Relacja procesowa}

Stan rzeczy, proces lub organ wyrażony w nadrzędniku dokonuje czynności wyrażonej w podrzędniku lub podlega czynności w nim wyrażonej. 
$A$ dokonuje B

ochrona uzupetniajaca

der subsidiäre Schutz

komitet doradczy

der beratende Ausschuss ochrona, która uzupełnia [inne środki ochronne wynikające $\mathrm{z}$ uzyskania statusu uchodźcy]

*Schutz, der subsidiär ist [relacja cechy wyróżniającej]

komitet, który doradza

Ausschuss, der berät

\section{(16) Relacja klasy}

Zaliczono tu grupę terminów, których człon określany [nadrzędnik] charakteryzuje się znaczeniem bardzo ogólnym, natomiast właściwa treść jest wyrażona za pomocą członu określającego [podrzędnika] (por. Beck-Tomasik w odniesieniu do relacji zakresowej). Wyraz określający doprecyzowuje wyraz określany i jest jednocześnie nośnikiem znaczenia.

B doprecyzowuje A

projekt aktu prawodawczego akt prawodawczy der Entwurf eines Gesetzgebungsakts Gesetzgebungsakt

misje zapobiegania konfliktom zapobieganie konfliktom Aufgaben der Konfliktverhütung Konfliktverhütung

\section{(17) Relacja gradacyjna}

Podrzędnik zwiększa lub zmniejsza obiekt / zjawisko wyrażone w nadrzędniku lub wyraża jego niekompletność / częściowość.

$B$ umniejsza A

$B$ zwiększa $A$

sita wyższa

höhere Gewalt

cesja częściowa

Teilabtretung 


\section{(18) Relacja cechy wy różniającej}

Obiekt, czynność lub stan rzeczy nazwany przez nadrzędnik jest dookreślony poprzez wyróżniającą go cechę wyrażoną w podrzędniku.

\section{B dookreśla A}

\section{glosowanie tajne}

die geheime Wahl

mienie ruchome

bewegliches Vermögen głosowanie, które odbywa się w sposób tajny Wahl, die geheim ist

mienie, które można przemieścić

Vermögen, das sich bewegen lässt

\section{Różnice w relacjach semantycznych}

Wyznacznikiem ekwiwalencji terminów prawnych i prawniczych jest przede wszystkim ich zgodność denotacyjna - zbiór desygnatów nazwy a także normatywna - konwencjonalne użycie w danym tekście prawnym lub sytuacji prawnej (por. Iluk 2012a: 162). Terminy wielowyrazowe zgodne denotacyjnie nie zawsze jednak zbudowane są w oparciu o taki sam sposób zespolenia i taką samą relację semantyczną między komponentami. W zestawieniach relacji semantycznych starałam się dobrać pary terminów o podobnej strukturze i relacji semantycznej. Poniżej zestawione zostaną przykładowe pary terminów o różnej strukturze i innej motywacji semantycznej.

Tabela 1. Pary polskich i niemieckich terminów ekwiwalentnych o różnej strukturze i różnej motywacji semantycznej

\begin{tabular}{|c|c|c|}
\hline Pary terminów PL/DE & Rodzaj relacji & Opis relacji \\
\hline środek zapobiegawczy & relacja celu & $\begin{array}{l}\text { środek zastosowany w celu zapobie- } \\
\text { gnięcia określonej czynności }\end{array}$ \\
\hline Vorsichtsmaßnahmen & relacja przyczyny & $\begin{array}{l}\text { Maßnahmen, die aus Vorsicht ergrif- } \\
\text { fen werden }\end{array}$ \\
\hline $\begin{array}{l}\text { zaświadczenie } \\
\text { o niekaralności }\end{array}$ & relacja tematyczna & $\begin{array}{l}\text { zaświadczenie dotyczące niefiguro- } \\
\text { wania w Krajowym Rejestrze Kar- } \\
\text { nym / zaświadczenie mówiące o tym, } \\
\text { że osoba nie była karana }\end{array}$ \\
\hline $\begin{array}{l}\text { polizeiliches } \\
\text { Führungszeugnis }\end{array}$ & $\begin{array}{l}\text { relacja czynnika dzia- } \\
\text { łającego }\end{array}$ & Die Polizei stellt das Zeugnis aus. \\
\hline
\end{tabular}


Tabela 1. Pary polskich i niemieckich... cd.

\begin{tabular}{|l|l|l|}
\hline Pary terminów PL/DE & \multicolumn{1}{|c|}{ Rodzaj relacji } & \multicolumn{1}{c|}{ Opis relacji } \\
\hline $\begin{array}{l}\text { postępowanie } \\
\text { dowodowe }\end{array}$ & relacja celu & $\begin{array}{l}\text { postępowanie, które ma na celu zebra- } \\
\text { nie dowodów }\end{array}$ \\
\hline Beweisaufnahme & relacja strony biernej & Beweise, die aufgenommen werden \\
\hline $\begin{array}{l}\text { rozwód } \\
\text { z orzekaniem o winie }\end{array}$ & relacja ornamentalna & $\begin{array}{l}\text { rozwód, orzeczony z podaniem osób } \\
\text { winnych rozpadu małżeństwa }\end{array}$ \\
\hline $\begin{array}{l}\text { Scheidung wegen Ver- } \\
\text { schuldens }\end{array}$ & relacja przyczynowa & $\begin{array}{l}\text { Scheidung, die wegen Verschuldens } \\
\text { eines Ehepartners erfolgt }\end{array}$ \\
\hline $\begin{array}{l}\text { poświadczenie } \\
\text { o niekaralności }\end{array}$ & relacja tematyczna & $\begin{array}{l}\text { poświadczenie dotyczące faktu nie by- } \\
\text { cia karanym prze osobę wnioskującą }\end{array}$ \\
\hline $\begin{array}{l}\text { polizeiliches } \\
\text { Führungszeugnis }\end{array}$ & $\begin{array}{l}\text { relacja czynnik } \\
\text { działającego }\end{array}$ & $\begin{array}{l}\text { Führungszeugnis, das von der Polizei } \\
\text { erteilt wird }\end{array}$ \\
\hline
\end{tabular}

Źródło: opracowanie własne

Z zaprezentowanych w artykule zestawień wynika, że ekwiwalentami polskich terminów wielowyrazowych mogą być zarówno analogiczne struktury wielowyrazowe, jak i struktury o innych formach elementów składowych czy innym sposobie zespolenia (np. kompozycje, frazy przyimkowe zamiast nominalnych etc.). Ekwiwalencja denotacyjna nie zawsze oznacza ekwiwalentną relację między komponentami. Przywołane przykłady wskazują, że różnice w relacjach semantycznych występują zarówno między ekwiwalentnymi terminami o strukturze innej jak i o podobnej. Ekwiwalenty w formie kompozycji mogą bazować na takich samych relacjach semantycznych kryzys spekulacyjny/ Spekulationskrise, jak i na odmiennych środek zapobiegawczy/Vorsichtsmaßnahmen.

\section{Podsumowanie}

Niniejszy artykuł stanowi przegląd relacji semantycznych zachodzących między komponentami polskich terminów wielowyrazowych z zakresu prawa i ich niemieckich ekwiwalentów. Zbadanie tych relacji miało na celu wskazanie tendencji do wyróżniania określonych cech nazywanych przedmiotów, zjawisk, instrumentów prawnych i ukazanie różnic kontrastywnych. 
Z zestawienia wynika, że polskie i niemieckie terminy wielowyrazowe mogą różnić się od siebie zarówno strukturalnie, jak i ze względu na istniejącą relację semantyczną między tworzącymi je komponentami, co może być przyczyną powstawania błędów interferencyjnych w procesie tłumaczenia czy w komunikacji specjalistycznej. Wyniki badań mogą mieć charakter aplikatywny w kształceniu tłumaczy i nauczycieli języka niemieckiego. Badanie niniejsze należy pogłębić $\mathrm{z}$ jednej strony o analizę ilościową w celu wyodrębnienia najbardziej produktywnej relacji semantycznej wśród terminów z zakresu prawa, z drugiej zaś w celu ustalenia tendencji w relacjach semantycznych polskich i niemieckich terminów z zakresu prawa.

\section{Bibliografia}

BAJEROWA I., 1972, Niektóre treści i metody socjolingwistyczne w historii języka, Biuletyn PTJ XXX, s. 27-39.

BAJEROwsKa A., 2014, Transferencja wiedzy specjalistycznej, Warszawa: IKL@.

Bizukojć K., 2011, Neue Nominalkomposita in deutschen Newsletter-Texten, Frankfurt a.M.: Peter Lang.

Burger H., 1998, Phraseologie. Eine Einführung am Beispiel des Deutschen, Berlin: Erich Schmidt Verlag.

Burger H., Buhofer A., Sialm A., 1982, Handbuch der Phraseologie, Berlin, New York: Walter de Gruyter.

Busse D., 2002, Wortkombinationen (Phraseologismen II), w: A. Cruse, F. Hundsnurscher, M. Job, R. Lutzeier (red.), Lexikologie. Ein internationales Handbuch zur Natur und Struktur von Wörtern und Wortschätzen, Berlin: Walter de Gruyter, s. 408-415.

Delplanque-Tchamitchian C., 1995, Wirtschaftsphraseologie: Strukturen des Sachverhalts im Text, In: Baur R.S., Chlosta Ch. (Hrsg.), Von der Einwortmetapher zur Satzmetapher, Bochum, S. 39-54.

Eichinger L., 2000, Deutsche Wortbildung: eine Einführung, Tübingen: Gunter Narr.

Engel U. ET AL., 2000, Deutsch-polnische kontrastive Grammatik, Warszawa: Groos.

FleisCher W., BARZ I., 2007, Wortbildung der deutschen Gegenwartssprache, Tübingen: Walter de Gruyter.

FLuCK H.-R., 1985, Fachsprachen. Einführung und Bibliographie, Tübingen: Franke.

GAJDA S., 1976, Rozwój polskiej terminologii górniczej, Opole: WSP.

GaJDA S., 1990, Wprowadzenie do teorii terminu, Opole: WSP. 
GóRnicz M., 2003, Terminologizacja tekstów specjalistycznych, w: B. Z. Kielar, S. Grucza (red.), Języki specjalistyczne. Lingwistyczna identyfikacja tekstów specjalistycznych, Warszawa: KJS UW s. 106-117.

Henzen W., 1957, Deutsche Wortbildung. Zweite, verbesserte Auflage, Tübingen: Max Niemeyer Verlag.

ILUK J., 2012a, Terminologia prawna i prawnicza z perspektywy translacyjnej, Studia Germanica Gedanensia 27, s. 161-175.

ILUK J., 2012b, Deutsche und polnische Rechtsterminologie aus translatorischer Sicht, w: P. Chmiel (red.), Verba docent, exempla trahunt! Zum 80. Geburtstag von Norbert Morciniec, Wrocław: WSF, s. 97-101.

Kilian A., Kilian A., 2009, Stownik języka prawniczego i ekonomicznego. Tom niemiecko-polski, Warszawa: Wolters Kluwer.

Kilian A., Kilian A., 2011, Słownik języka prawniczego i ekonomicznego. Tom polsko-niemiecki, Warszawa: Wolters Kluwer.

Lukszyn J., 2002, Języki specjalistyczne. Słownik terminologii przedmiotowej, Warszawa: KJS UW.

Lukszyn J., ZMARZer W., 2006, Teoretyczne podstawy terminologii, Warszawa: KJS UW.

MorCINIEC N., 1964, Die nominalen Wortzusammensetzungen in den westgermanischen Sprachen, Prace WTN, Seria A, Nr. 99, Wrocław.

MorcinieC N., 2012, Vita in Linguis. Schriften zur Germanistik und Niederlandistik, Wrocław, Dresden: Oficyna Wydawnicza ATUT, Neisse Verlag.

Ortner H., Ortner L. 1984, Zur Theorie und Praxis der Kompositaforschung. Mit einer ausführlichen Bibliographie, Tübingen: Gunter Narr.

Ortner L. ET AL., 1991, Deutsche Wortbildung. Typen und Tendenzen in der Gegenwartssprache. Vierter Hauptteil: Substantivkomposita, Berlin: Walter De Gruyter.

PaŁuszYŃska E., 1998, Wielowyrazowe jednostki leksykalne jako terminy zoologiczne, Acta Universitatis Lodziensis. Kształcenie Polonistyczne Cudzoziemców 10, s. 395-408.

Siewert K., 2010, O tworzeniu terminów prawnych na przykładzie terminologii polskiego i niemieckiego prawa handlowego, Legilingwistyka Porównawcza 3, s. 81-91.

Sitarski, A. 1981, O kompresji strukturalnej $w$ zakresie polskiej $i$ rosyjskiej terminologii językoznawczej, Studia Rossica Posnaniensia 16, s. 183-191.

Starzec A., 1984, Rozwój polskiej terminologii motoryzacyjnej (od początku do 1945 roku), Opole: WSP.

Temmerman R., 2000, Towards New Ways of Terminology Description. The Sociocognitive Approach, Amsterdam: John Benjamins Publishing. 
Tomasik-Beck J., 1992, Struktura semantyczna terminów wielowyrazowych, Poradnik. Językowy 45, s. 47-59.

Tomaszczyк J., 2014, Holistyczny model terminologii, Praktyka i teoria informacji naukowej i technicznej 22/1, s. 57-65.

WoźNIaK J., 2016, Fachphraseologie am Beispiel der deutschen und der polnischen Fassung des Vertrags von Lissabon, Gdańsk: Peter Lang.

\section{Semantic relationships in the Polish and German legal multi-word terms (summary)}

The tendency to use multi-word terms is different in the Polish and German languages for specific purposes. The studies of both languages indicate high productivity of syntagmatic derivation in Polish terminology, whereas in German terminology the preferred word formation process is composition. For both the multi-word terms and compound terms not only the structural relations between the components are significant, but also the semantic relationships between the head and the modifier of the term. In Polish and German literature a number of attempts have been made to classify the semantic relationships of multi-word and compound terms. The purpose of this article is to present the selected semantic relationships between Polish legal terms and to show similarities and differences between Polish terms and their equivalents in German. 
